\title{
Ultra high strength steel sandwich for lightweight applications
}

\author{
Samuel Hammarberg ${ }^{1}$ (D) Jörgen Kajberg ${ }^{1} \cdot$ Simon Larsson $^{1} \cdot$ Pär Jonsén ${ }^{1}$
}

Received: 20 January 2020 / Accepted: 15 April 2020 / Published online: 8 May 2020

(C) The Author(s) $2020 \quad$ OPEN

\begin{abstract}
Methods for reducing weight of structural elements are important for a sustainable society. Over the recent years ultra high strength steel (UHSS) has been a successful material for designing light and strong components. Sandwich panels are interesting structural components to further explore areas where the benefits of UHSS can be utilized. The specific properties of sandwich panels make them suitable for stiffness applications and various cores have been studied extensively. In the present work, bidirectionally corrugated UHSS cores are studied experimentally and numerically. A UHSS core is manufactured by cold rolling and bonded to the skins by welding. Stiffness is evaluated experimentally in three-point bending. The tests are virtually reproduced using the finite element method. Precise discretization of the core requires large amounts of computational power, prolonging lead times for sandwich component development, which in the present work is addressed by homogenization, using an equivalent material formulation. Input data for the equivalent models is obtained by characterizing representative volume elements of the periodic cores under periodic boundary conditions. The homogenized panel reduces the number of finite elements and thus the computational time while maintaining accuracy. Numerical results are validated and agree well with experimental testing. Important findings from experimental and simulation results show that the suggested panels provide superior specific bending stiffness as compared to solid panels. This work shows that lightweight UHSS sandwiches with excellent stiffness properties can be manufactured and modeled efficiently. The concept of manufacturing a UHSS sandwich panel expands the usability of UHSS to new areas.
\end{abstract}

Keywords UHSS · Sandwich · Lightweight · Modeling · Bidirectional core · Representative volume element (RVE)

\section{Introduction}

There is an increasing requirement from the global market for lightweight structures to reduce energy consumption and emissions, and to keep the product development costs low and the lead times short. Steel is commonly used in many sectors because of its favorable relationship between price and strength. Although it is not considered a light material, its strengths can be utilized to manufacture products of low weight. In particular, ultra high strength steel (UHSS) is attractive for weight reduction. In the automotive industry, UHSS is used for body in white parts due to its high strength but also in many cases high ductility. Hence, UHSS is often considered for passive safety components due to high crashworthiness. Although, UHSSs are mainly used by the automotive industry their superiors properties are also of interest for the aerospace industry [1-7] as well as heavy machinery and ship building $[8,9]$. Some UHSS grades are intended to be cold-formed to the final part whereas other grades, such as boron steels, are formed by press-hardening. Presshardening is a hot stamping operation combined with a quenching step resulting in components with mainly martensitic microstructures and thereby high strength and also very high shape accuracy. Additionally, by varying the temperature in the forming tools, the cooling

Samuel Hammarberg, samuel.hammarberg@ltu.se | 'Luleå University of Technology, Universitetsvägen, Luleå, Sweden. 
rates in the blank may be controlled, resulting in components with varying final microstructures and thereby varying mechanical properties. Components with tailored properties are desirable for car safety parts due to their structural integrity and ability to absorb energy. A general review on many aspects of hot stamping and tailored properties is given by [10-13]. A lot of work has been done studying the hot-stamping process with respect to both experimental characterization and numerical modeling, such as Bergman [14], Eriksson et al. [15], Bergman and Oldenburg [16], Åkerström et al. [17], Åkerström and Oldenburg [18], Åkerström et al. [19] . Further work regarding properties such as fracture and fatigue in UHSS has been carried out by e.g. Östlund et al. [20, 21], Golling et al. [22], Parareda et al. [23]. UHSS has been a good candidate for lightweight components due to its high strength and low productions costs. In order to meet weight restrictions, superior material properties are sometimes not enough and innovative solutions such as sandwich panels must be considered. Sandwich panels with lightweight cores are suitable structural elements when high strength to weight ratio is of importance in stiffness applications [24]. Typically, this type of structure consists of two outer, generally thin, face-plates or skins enclosing a lightweight core. Ideally, the core material is much thicker than the much stiffer and stronger face material. Hence, the beneficial properties of UHSS, make those grades very good candidates to be used in sandwich solutions. Typically, cost and time efficient virtual methods such as the finite element method, are used to simulate the manufacturing processes and to predict the final product properties. However, the implementation of sandwich solutions brings new challenges in modeling due to, e.g. use of mixed materials and delamination. Numerical aspects, related to the complex geometries resulting in an unreasonable number of finite elements, causing long computational times, for precise discretization during component development, must be considered for the sandwich concept to be attractive.

A wide variety of core materials have been presented in the literature. Common core materials are foam, honeycomb and corrugated sheets. Reyes et al. [25] studied foams for energy absorption with a constitutive model based on Deshpande and Fleck [26]. Further work regarding foam is performed by Zhang et al. [27] and Rostamiyan and Norouzi [28] where the former is dedicated to experimental characterization and modeling whereas the latter investigates the properties of foam in a sandwich structural element. Modeling and validation of energy absorption in foam is performed by Guo et al. [29]. Honeycomb cores have been studied by Aktay et al. [30], Nayak et al. [31], Liu et al. [32] and have been shown to exhibit excellent lightweight properties. Other types of laminated structures are also possible such as fiber reinforced plastics or metal based structures such as the aluminum laminate evaluated in three-point bending presented by Wang et al. [33].

Sandwich panels with corrugated cores have been studied by several authors. Typically, the ABD-matrix, derived in classical laminate theory (see e.g. Jones [34]), is suggested for numerically representing a homogenized and equivalent core material allowing decoupling of bending and stretching. What generally varies is the manner in which the components of the ABD-matrix are determined. Biancolini [35] propose using a numerical approach for determining the ABD-matrix and good agreement is found between the proposed method and data available in the literature. Kress and Winkler [36] propose an analytic approach for determining equivalent ABD-matrix for circular sections. Manufacturing and experimental testing of the mechanical properties of corrugated cores have been done by Li [37] and Dayyani et al. [38]. Li [37] performed testing in compression, shear and bending. Dayyani et al. [38] manufactures and evaluates corrugated panels in bending and tension through analytic and numerical methods which are also validated experimentally. Further methods for analytic determination of the equivalent ABDmatrix are proposed by Xia et al. [39], Ye et al. [40], Marek and Garbowski [41], Park et al. [42] where the most robust derivations seems to be given by Ye et al. [40]. Bidirectionally corrugated cores have been presented by Leekitwattana [43], Besse and Mohr [44], Daliri and Zeinedini [45]. Chomphan and Leekitwattana [43] investigates the stress response of bidirectionally corrugated cores under threepoint bending whereas Besse and Mohr [44] studies the shear properties of such cores. Daliri and Zeinedini [45] experimentally investigates flexural behavior of bidirectionally corrugated cores based on fiber reinforced plastics.

When using a numerical approach for determining the ABD-matrix, a representative volume element (RVE) is typically studied. The RVE is subjected to certain loading conditions from which the constants in the matrix are determined. In previous works, such as Bartolozzi et al. [46] and Park et al. [42], traditional homogeneous boundary conditions (HBC) were used. Such boundary conditions tend to over/under predict stiffness for orthotropic RVEs (Suquet [47], Xia et al. [48], Omairey et al. [49]) since periodicity is not achieved. Instead, periodic boundary conditions (PBCs) are recommended.

For sandwich panels with corrugated cores to be of interest for the industry, efficient manufacturing processes are necessary to keep down both product development costs and lead times. Fiber reinforced composite materials posses many advantages over steel, such as high strength to weight ratio, corrosion resistance and design flexibility, but the material itself and its manufacturing process is, 
however, more costly and labor intensive. It is also more difficult to produce such components in a continuous manner which is not the case for components based on steel.

This paper introduces a novel sandwich concept, based on UHSS, with a bidirectionally corrugated core. A pilotscale mill is utilized to manufacture the UHSS core and the sandwich is tested in three-point bending. The finite element method (FEM) is used to numerically reproduce the bending test. An equivalent material formulation, based on the ABD-matrix, is adopted for homogenizing the core greatly reducing computational time compared to precise discretization. The ABD-matrix is determined by analyzing an RVE subjected to PBCs. The objective of the present work is to investigate if lightweight UHSS sandwiches with high performance can be manufactured in a continuous manner and if such panels can be modeled efficiently by so-called homogenization.

\section{Sandwich concepts}

Two types of novel sandwich concepts, with bidirectionally corrugated cores based on UHSS, are studied in the present work, see Fig. 1. A specimen of the double sinusoidal core, Fig. 1a, is manufactured whereas the core with flattened peaks, Fig. 1b, is only evaluated numerically. The benefit of the flattened peaks is a larger contact surface between core and skins allowing for a stronger bond. Thus, it is of interest to compare mechanical properties between the two types of cores.

The double sinusoidal is henceforth referred to as Type A whereas the core with flattened peaks will be referred to as Type B. Formability of bidirectionally corrugated cores is typically better than sandwiches with single corrugated cores. Products based on the latter concept are usually formed by only bending around the direction of corrugations because of too high stiffness in the perpendicular direction. Components of boron steels, formed by presshardening, are widely used by the car industry. This type of bidirectionally corrugated core might therefore be of interest for e.g. battery casing for electric vehicles due to high strength and reasonable formability.

\section{Experimental study}

The Type A sandwich is based on UHSS (22MnB5) and the bidirectionally corrugated core is manufactured by cold rolling in a pilot-scale mill. Prior to cold rolling, the sandwich constituents are heated to $950^{\circ} \mathrm{C}$ and quenched, forming a mainly martensitic microstructure with UHSS properties. The UHSS exhibits a $\mathrm{Rp}_{0.2}$ of $1050 \mathrm{MPa}$ and an ultimate strength of $1550 \mathrm{MPa}$. Sheet thicknesses are 0.4 $\mathrm{mm}$. In Fig. 2a the rolls are presented and a manufactured specimen of the Type A core is presented in Fig. 2b. A trigonometrical function (Eq. 1) describes the final geometry of the Type A core after cold rolling. The $x, y$ and $z$

Fig. 1 Sandwich concepts

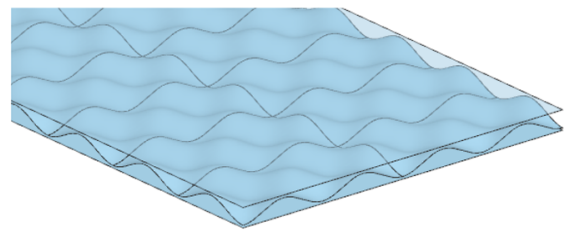

(a) Isometric view of the core with a double sinusoidal (Type A).

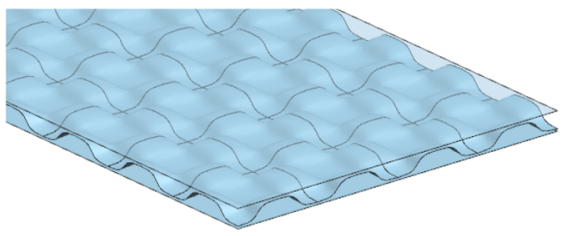

(b) Isometric view of the core with flattened peaks (Type B).

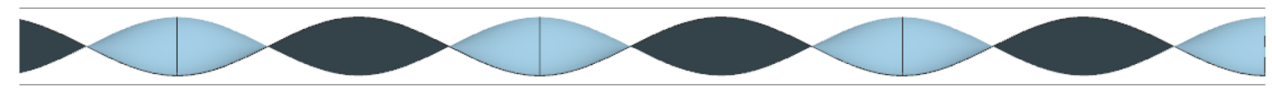

(c) Side view of the core with a double sinusoidal (Type A).

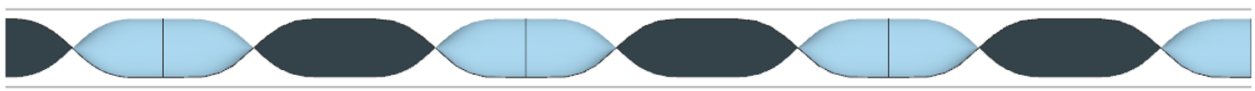

(d) Side view of the core with flattened peaks (Type B). 
Fig. 2 Rolls (a) used for manufacturing a specimen of the Type A UHSS core (b)

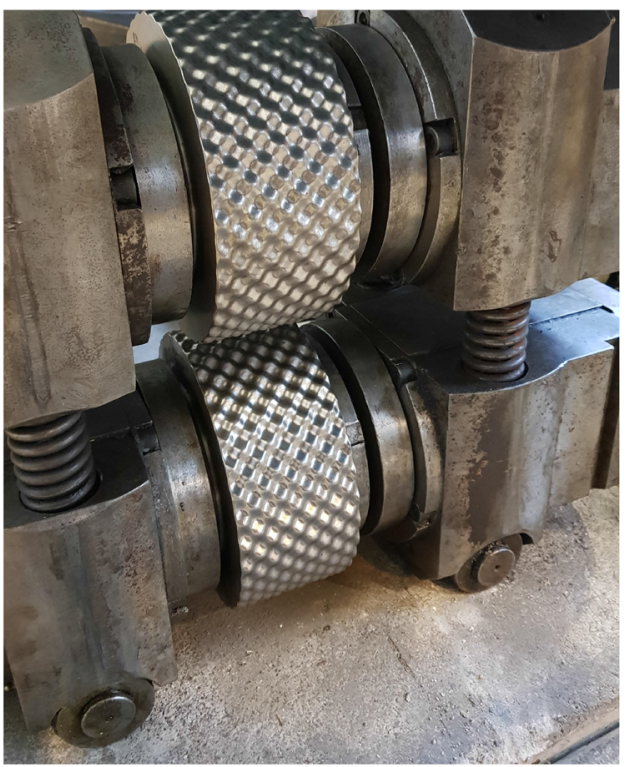

(a) Patterned rolls. Width of rolls are $75 \mathrm{~mm}$ and diameter is $180 \mathrm{~mm}$.

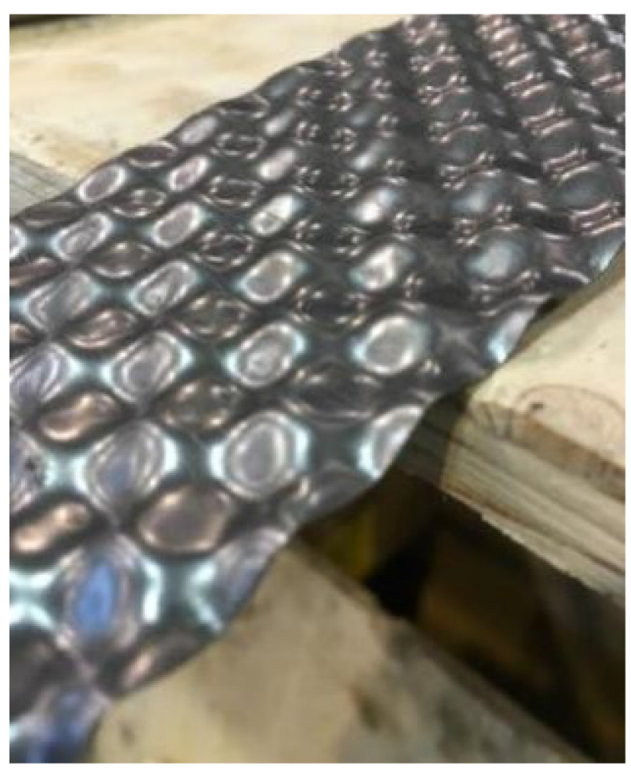

(b) Type A core. coordinate axes are in the length, width, and thickness direction respectively.

$$
\begin{gathered}
z(x, y)=A \cdot \sin \left(2 \frac{\pi}{\lambda} x\right) \cdot \sin \left(2 \frac{\pi}{\lambda} y\right), \text { where } \\
0 \leq x \leq 16 \lambda \mathrm{mm}, 0 \leq y \leq 4 \lambda \mathrm{mm} .
\end{gathered}
$$

The amplitude, $A$, is $1.45 \mathrm{~mm}$, and the wavelength, $\lambda$, is $15.44 \mathrm{~mm}$, resulting in a width and length of 61.8 and $247 \mathrm{~mm}$ respectively. Joining of the core and skins is performed by laser welding. The first layer is welded from the inside of the sandwich whereas the second layer is welded from the outside. A finished specimen of the Type A sandwich panel is presented in Fig. 3, where the welding pattern on the skin can be seen.

Evaluation of flexural stiffness is done under three-point bending using a servo-hydraulic testing machine, Instron 1272, see Fig. 4. Applied force and displacement are measured by the internal loading cell of the testing machine and a laser position sensor, respectively. For consistency three manufactured specimens of the Type A sandwich are tested. The punch is given a displacement of $3 \mathrm{~mm}$. Diameters of punch and supports are $25 \mathrm{~mm}$, with the supports placed $300 \mathrm{~mm}$ apart.
Fig. 3 Manufactured specimen of a Type A sandwich panel with bidirectionally corrugated core

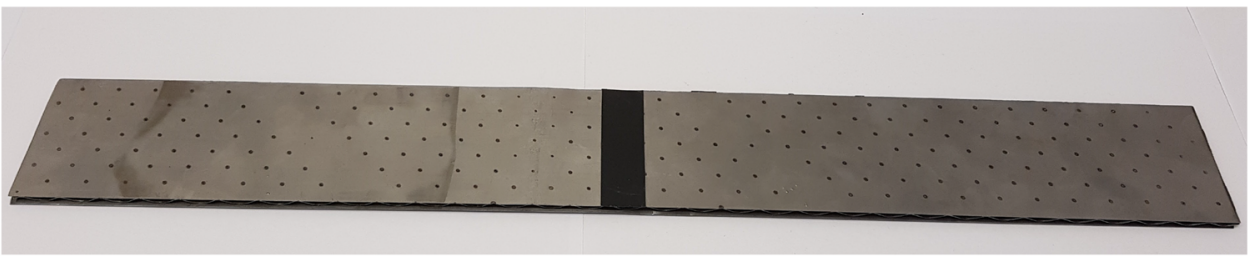

(a) Sandwich panel where the dots on top correspond to the welds.

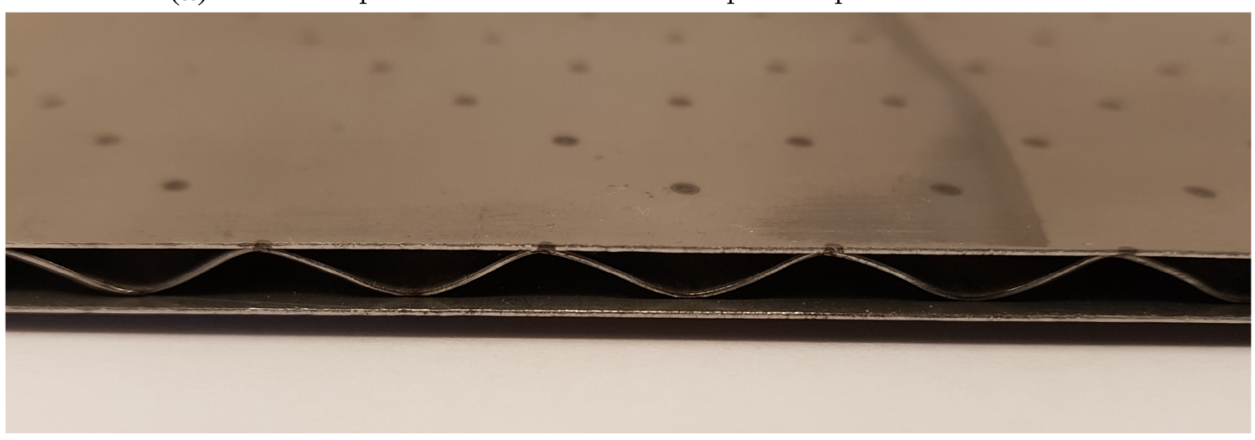

(b) Zoom in of sandwich panel. 


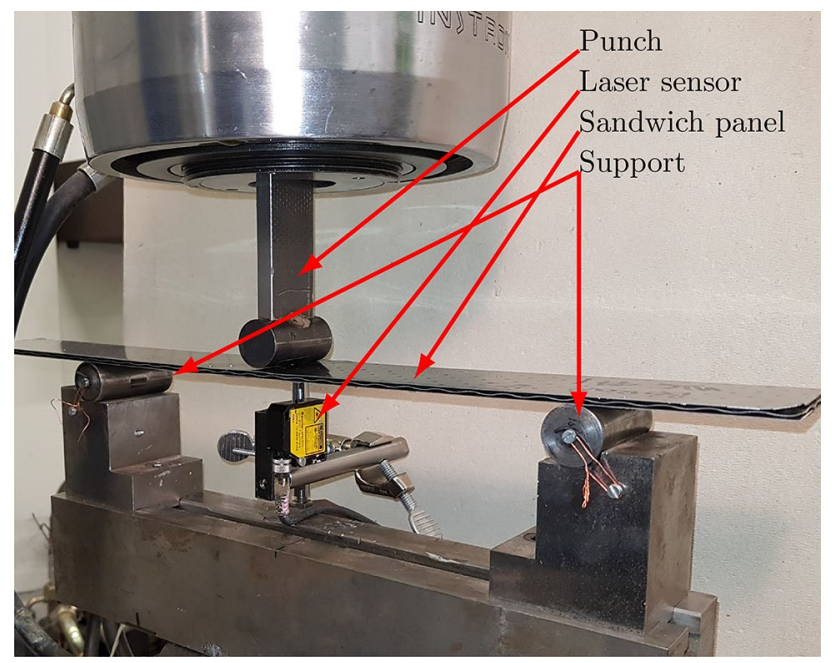

Fig. 4 Experimental setup for three point bending of a sandwich panel

\section{Modeling}

In the current section the modeling approach is presented. Detailed finite element models of the sandwiches are presented. To illustrate the superior bending stiffness of the suggested sandwiches, a comparison is made with a solid steel panel of equivalent weight. The complex geometries of the cores require a large amount of finite elements for precise discretization leading to long computational time. This issue is addressed by a second finite element model with a homogenized panel based on an equivalent material formulation using the $\mathrm{ABD}$-matrix derived in laminate theory. Each component of the ABD-matrix is determined by analyzing a representative volume element (RVE) subjected to periodic boundary conditions (PBC). All simulations are run using the multi-physics solver LS-DYNA [50].

\subsection{Detailed sandwich model}

The finite element model of the sandwiches in three-point bending are presented in Fig. $5 \mathrm{a}$ where the side view of the two types of cores are shown in Fig. 5c, d. A symmetry condition is utilized so that only half the three-point bending setup is modeled in order to reduce computational time, see Fig. 5a. Fully integrated shell elements with five integration points through the thickness are used. Three different mesh sizes are tested for convergence: 2,1 , and $0.5 \mathrm{~mm}$. In Fig. $5 \mathrm{~b}$ a zoomed in figure is presented for the mesh size of $0.5 \mathrm{~mm}$ illustrating the large number of elements required for precise discretization of the core. $\mathrm{A}$ thickness of $0.4 \mathrm{~mm}$ is used for all sheets of the sandwich. A linear elastic constitutive model with density, Young's modulus and Poisson's ratio set to $7800 \mathrm{~kg} / \mathrm{m}^{3}, 210 \mathrm{GPa}$ and 0.3 respectively, is adopted since plasticity is not considered for the current application. In order to model the welds between core and skins beam elements with the same material data as the sandwich are used. Support and punch are modeled as rigid bodies. Contact between punch/support and sandwich is handled by a penalty based contact algorithm and the punch is given a displacement of $3 \mathrm{~mm}$. An implicit time integration scheme is utilized since quasi-static conditions are assumed.

\subsection{Equivalent sandwich model}

Reduction of number of element is done by introducing an equivalent material formulation. A constitutive routine is utilized where the ABD-matrix, Eq. (13), is given as input data. For the core, the components of the ABD-matrix are determined according to Sect. 4.4 whereas for the face plates the ABD-matrix is determined analytically. The entire sandwich is represented by summation of the ABDmatrix of each layer. This makes it possible to represent the equivalent sandwich with only one layer of shell elements, drastically reducing the number of finite elements. The equivalent model is evaluated in a similar three-point bending setup as the detailed models of Fig. 5 .

\subsection{Periodic boundary conditions}

The corrugated core consists of periodic arrays of RVEs. In order to maintain periodicity when characterizing a single RVE, PBCs are necessary, see e.g. Suquet [47], Xia et al. [48], Omairey et al. [49]. To clearly illustrate the strength and necessity of adopting PBC the simple periodic structure of Fig. 6 is used where the unit cell is used as an RVE. The RVE is subjected to in-plane shearing for both homogeneous boundary conditions (HBC) and PBC. The bulk material consists of solid steel and the inclusion is considered to be air. A description of PBC will be given in accordance with Suquet [47] and Xia et al. [48]. The local strain, $\epsilon_{i k}$, is split into its average, $\bar{\epsilon}_{i k}$, and a fluctuating term, $\epsilon_{i k}\left(u^{*}\right)$, where $u^{*}$ is a periodic displacement field

$\epsilon_{i k}=\bar{\epsilon}_{i k}+\epsilon_{i k}\left(u_{i}^{*}\right)$

and the periodicity condition for displacement on the boundary is obtained as

$u_{i}=\bar{\epsilon}_{i k} x_{k}+u_{i}^{*}$.

where $x_{i}$ is the coordinate and $i, k=(1,2,3)$. For a parallelepiped RVE, as in Fig. 6 , the periodicity implies a coupling between nodes on opposite sides of the RVE. A convention typically adopted is that nodes on faces with normals in the positive direction of a coordinate axis is denoted with a plus sign. In a similar manner, nodes on faces with 
Fig. 5 Detailed finite element model of three-point bending of Type A sandwich

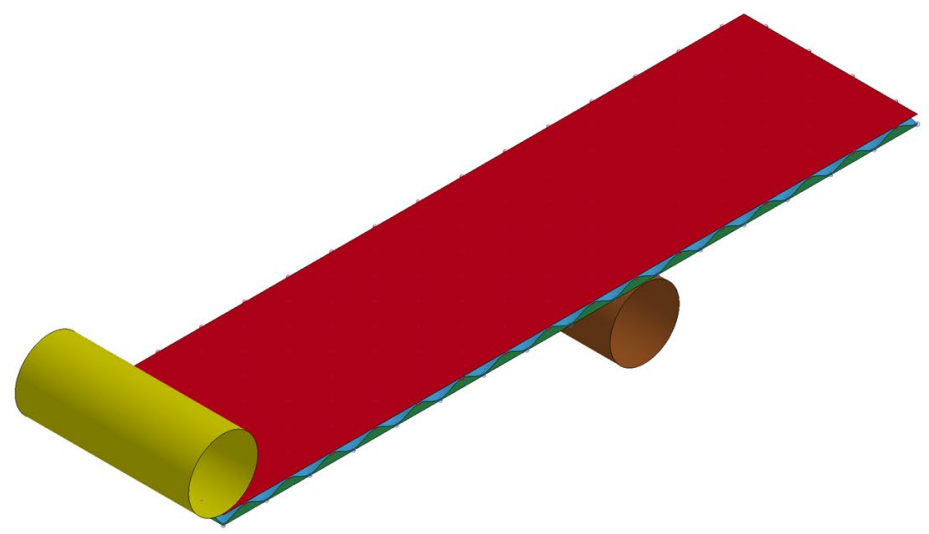

(a) One half of the experimental setup is modeled due to symmetry.

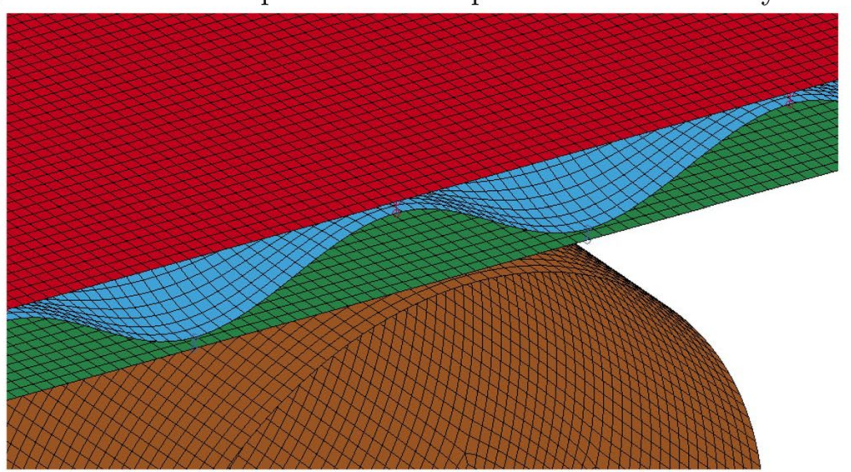

(b) Mesh size of $0.5 \mathrm{~mm}$.

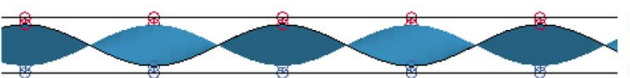

(c) Side view of Type A.

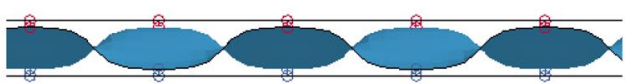

(d) Side view of Type B. normals in the negative direction of a coordinate axis is denoted with a minus sign. Thus, from Eq. (3) the following equations can be formulated for nodes on the positive and negative faces of the RVE

$u_{i}^{+}=\bar{\epsilon}_{i k} x_{k}^{+}+u_{i}^{*}$

$u_{i}^{-}=\bar{\epsilon}_{i k} x_{k}^{-}+u_{i}^{*}$.

Equations (4) and (5) are rewritten as

$u_{i}^{+}-u_{i}^{-}=\bar{\epsilon}_{i k} x_{k}^{+}+u_{i}^{*}-\bar{\epsilon}_{i k} x_{k}^{-}+u_{i}^{*}=\bar{\epsilon}_{i k}\left(x_{k}^{+}-x_{k}^{-}\right)=\bar{\epsilon}_{i k} \Delta x_{k}$

which implies that each node on the plus face is coupled to its image node on the minus face and their distance is controlled by the average stretch/contraction or shear deformation of the RVE. Xia et al. [48] rewrites this as

$u_{i}^{j+}-u_{i}^{j-}=c_{i}^{j}$

where $i$ and $j$ relate to the degree of freedom (DOF) and the face connected to the node, and $i, j=(1,2,3)$ for a three dimensional RVE. For $i=j$ stretching/contraction occurs whereas shear deformation is considered if $i \neq j$. Since the periodic and unknown term, $u_{i}^{*}$ is not present in Eq. (7), it makes implementation easier, and constrain equations within the finite element software can be used. It should be noted that nodes on vertices and edges must

\section{SN Applied Sciences}




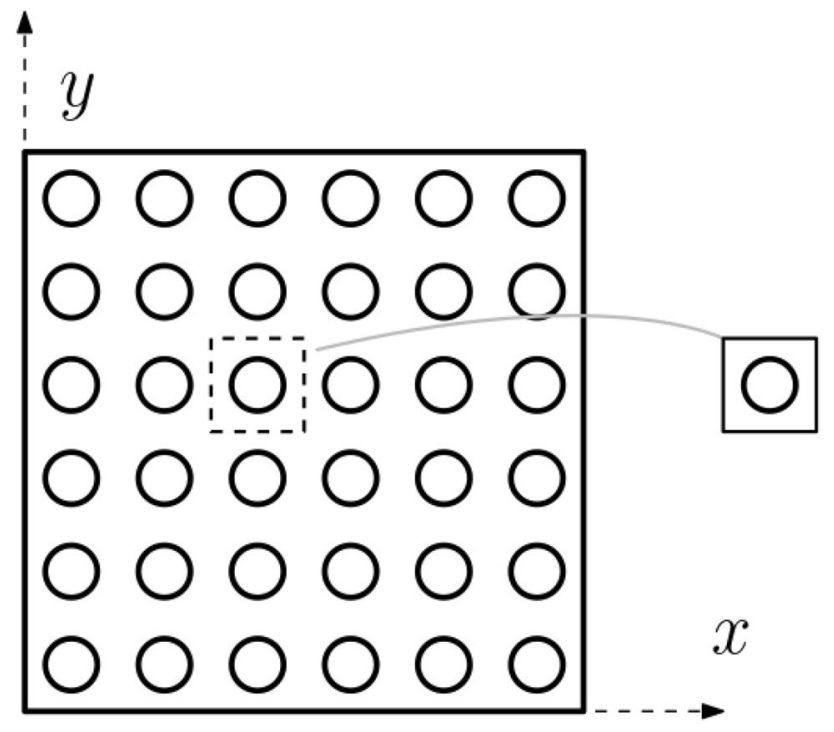

Fig. 6 An example of a material containing several inclusions. Due to the periodicity a unit cell is easily defined (right hand side of image)

fulfill periodicity in two or more directions and must therefor be handled differently to avoid overconstraining the model.

In the present work, a MATLAB script is created to couple each node pair on opposite surfaces, according to Eq. (7). The constant, $c_{i}^{j}$, corresponds to the displacement of a dummy node in accordance with $\mathrm{Wu}$ and $\mathrm{Hu}$ [51] and Liu et al. [52]. Thus, there is one dummy node for each in-plane translational DOF and the macroscopic strain constraint is prescribed through the dummy nodes. By utilizing the dummy nodes homogenized quantities, such as average stress and strain, can be determined without volume averaging the quantities of interest. This process is started by determining the deformation gradient, $F_{i j}$, defined as

$F_{i j}=\frac{\partial u_{i}}{\partial x_{j}}+\delta_{i j}$

which can be obtained for the RVE by expressing it in terms of the dummy nodes as

$F_{i j}=\frac{c_{i}^{j}}{\Delta x_{j}}+\delta_{i j}$ (no summation).

$\delta_{i j}$ and $\Delta x_{i}$ are the Kronecker delta and the dimension of the RVE respectively. It should be mentioned that Eq. (9) is symmetric in the present context. From the dummy nodes the forces, $f_{i j}$, can be extracted. The macroscopic first PiolaKirchhoff stress tensor, $P_{i j}$, is then obtained as
$P_{i j}=\left[\begin{array}{lll}\frac{f_{11}}{\Delta x_{2} \Delta x_{3}} & \frac{f_{12}}{\Delta x_{2} \Delta x_{3}} & \frac{f_{13}}{\Delta x_{2} \Delta x_{3}} \\ \frac{f_{21}}{\Delta x_{3} \Delta x_{1}} & \frac{f_{22}}{\Delta x_{3} \Delta x_{1}} & \frac{f_{23}}{\Delta x_{3} \Delta x_{1}} \\ \frac{f_{31}}{\Delta x_{1} \Delta x_{2}} & \frac{f_{32}}{\Delta x_{1} \Delta x_{2}} & \frac{f_{33}}{\Delta x_{1} \Delta x_{2}}\end{array}\right]$.

Just like the deformation gradient, the first Piola-Kirchhoff stress tensor is symmetric in the present context. The Green-Lagrange strain tensor, $\boldsymbol{E}$, is obtained from the deformation gradient according to

$\boldsymbol{E}=\frac{1}{2}\left(\boldsymbol{F}^{T} \boldsymbol{F}-\boldsymbol{I}\right)$

where $\boldsymbol{I}$ is the identity tensor. The Cauchy stress tensor is obtained as

$\sigma=J^{-1} \boldsymbol{P} \boldsymbol{F}^{T}$

with $J$ being the determinant of the deformation gradient. From the Green-Lagrange strain, Eq. (11), and the Cauchy stress, Eq. (12), the homogenized constitutive relationship for various loading conditions can be determined.

\subsection{Characterization of cores}

Reduction of computational time is done by using an equivalent material for the core. The equivalent material formulation is based on the ABD matrix, derived in laminate theory see e.g. Jones [34], and is given in Eq. (13). It should be mentioned that the bending-extension coupling, $B_{i j}$, is zero for the present case.

$\left[\begin{array}{l}N_{x x} \\ N_{y y} \\ N_{x y} \\ M_{x x} \\ M_{y y} \\ M_{x y}\end{array}\right]=\left[\begin{array}{cccccc}A_{11} & A_{12} & 0 & B_{11} & B_{12} & 0 \\ A_{12} & A_{22} & 0 & B_{12} & B_{22} & 0 \\ 0 & 0 & A_{66} & 0 & 0 & B_{66} \\ B_{11} & B_{12} & 0 & D_{11} & D_{12} & 0 \\ B_{12} & B_{22} & 0 & D_{12} & D_{22} & 0 \\ 0 & 0 & B_{66} & 0 & 0 & D_{66}\end{array}\right]\left[\begin{array}{c}\epsilon_{x x} \\ \epsilon_{y y} \\ \epsilon_{x y} \\ \kappa_{x x} \\ \kappa_{y y} \\ \kappa_{x y}\end{array}\right]$.

The elastic constants of the ABD-matrix, presented in Eq. (13), are determined by analyzing an RVE for each of the two bidirectionally corrugated cores, see Fig. 7. An RVE is typically defined as the smallest volume of a material, containing enough information to be representative of the material at the macro scale. Thus, by characterizing the RVEs the macro scale mechanical properties are determined. Periodic boundary conditions, described in Sect. 4.3 , are applied by utilizing constraint equations within the finite element software. Displacements are prescribed to dummy nodes, and Fig. 8 indicates their directions. Several mesh sizes are checked for mesh independent results. This is done for both RVEs. Fully integrated shell elements are adopted with five integration points through the thickness. An implicit time integration scheme is used. 
Fig. 7 Representative volume elements (RVEs) used for mechanical characterization of core

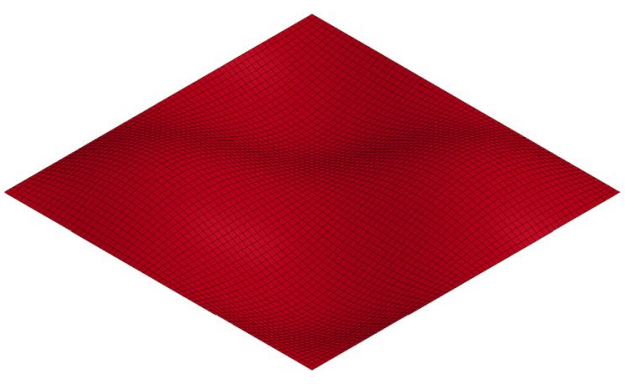

(a) Type A.

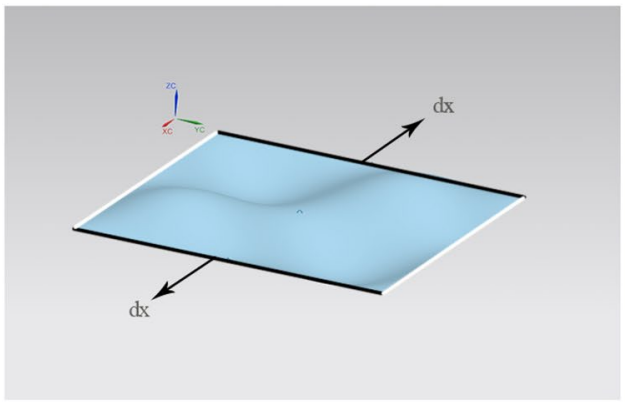

(a) A11.

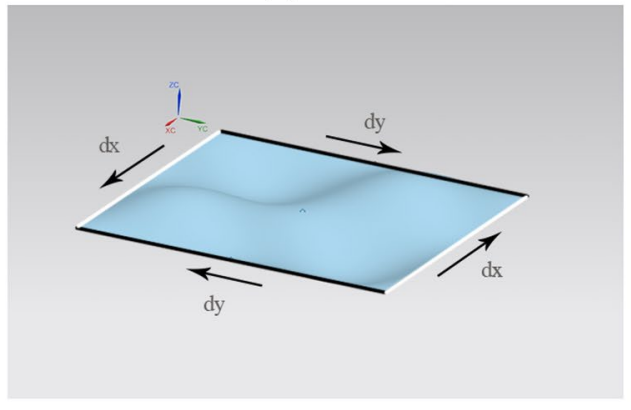

(c) A66.

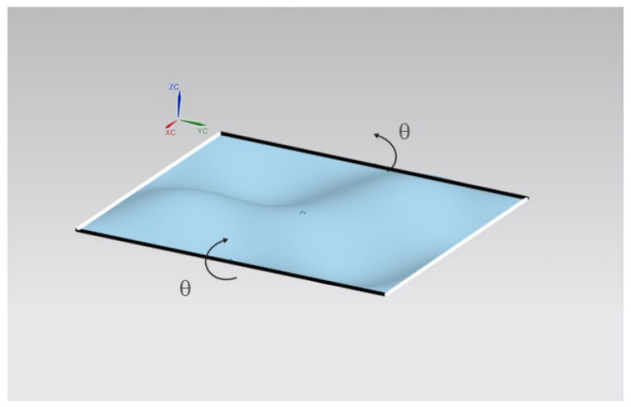

(e) D22.

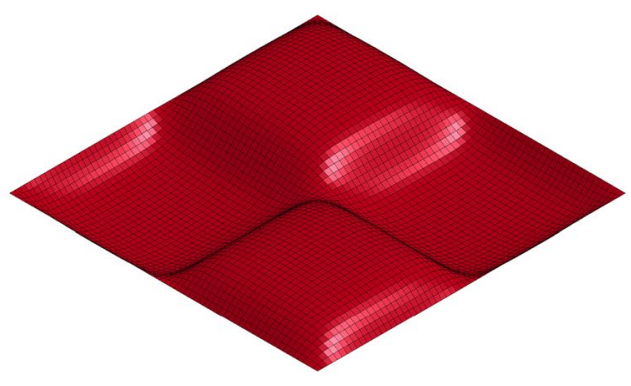

(b) Type B.

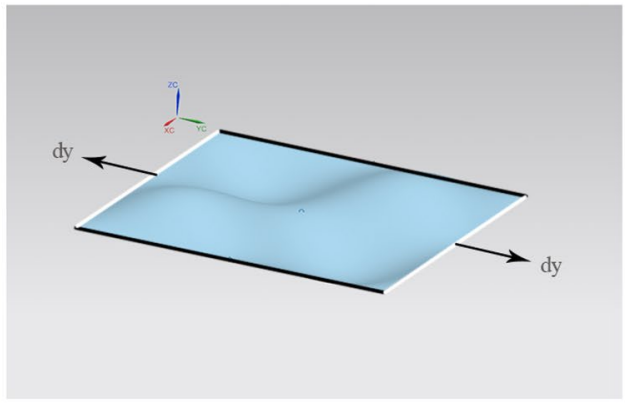

(b) A22.

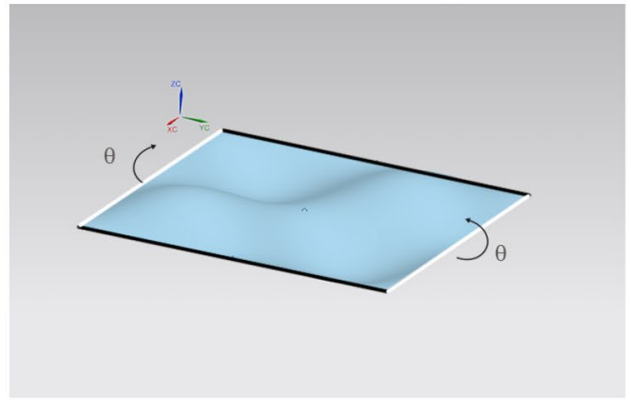

(d) D11.

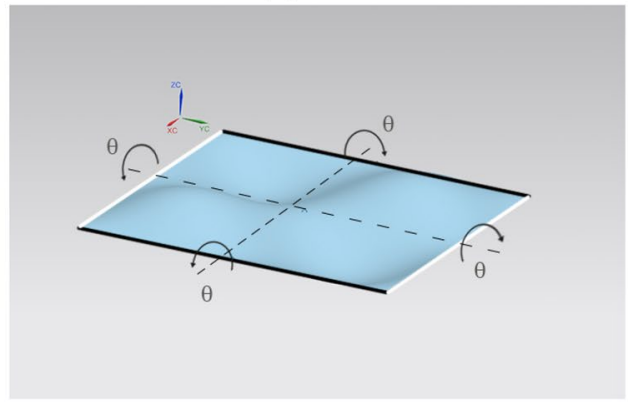

(f) $\mathrm{D} 66$.
Each RVE is subjected to six unique load cases, see Fig. 8. $A_{11}$ is determined by constraining the nodes except for in the $x$-directions, and displacing nodes on the $x^{+}$and $x^{-}$edges of the RVE, giving rise to an equivalent state of uniaxial strain. $A_{11}$ and $A_{12}$ are then obtained as

$A_{11}=N_{11} / \epsilon_{11}$
$A_{12}=N_{12} / \epsilon_{11}$

where $N_{11}$ and $N_{12}$ are force per unit length, obtained by integrating the stress from Eq. (12) over the thickness. Due to the symmetry of the RVE it is noted that

$A_{11}=A_{22}$. 
$A_{66}$ is determined by subjecting the RVE to an equivalent shear stress state. This is achieved by displacing each node set according to Fig. $8 \mathrm{c}$. The force response per unit length, $N_{66}$, and $\gamma_{x y}$ are found from the simulation and $A_{66}$ is determined as

$A_{66}=N_{66} / \gamma_{x y}$.

In a similar manner $D_{11}, D_{12}, D_{22}$ and $D_{66}$ are determined by subjecting the RVE to the corresponding load cases of Fig. 8.

\section{Results}

In the present section the obtained experimental and numerical results for the UHSS sandwich panels of this work are presented. In order to investigate the necessity of PBCs for the present work, a comparison is made between $\mathrm{HBC}$ and $\mathrm{PBC}$ for both the illustrative example in Fig. 6 and the Type A core. In Fig. 9 the RVE of the periodic structure in Fig. 6 is subjected to in-plane shearing. Initially it is noted that the boundaries of Fig. $9 a$, b do not remain plane, which is a first indication of fulfilled periodicity. Furthermore, it can be seen that the the stress field is independent of number of unit cells as expected for PBC. A final check can be made that the force response of Fig. $9 a$ is half of the force in Fig. 9b, which holds true. Thus the response is independent on the number of unit cells used in the RVE which indicates that periodicity is maintained under the PBC used in this work. The same RVEs are subjected HBC, see Fig. $9 c$, $d$. It is clear that the stress fields vary and thus periodicity is not maintained. From the force response, it is seen that a softer response is obtained for the larger RVE, as expected. It should be noted that a larger RVE than the one presented in Fig. $9 \mathrm{~d}$ is necessary for the response to converge toward the results obtained for PBCs. In Fig. 10 the Type A RVE is subjected to both PBC (Fig. 10a, b) and HBC (Fig. 10c, d). Is is observed that the obtained stress fields are similar for both $P B C$ and $H B C$. For PBC the periodicity is clearly maintained whereas slight boundary effects are observed for HBC. From the force response obtained for PBC, see Fig. 10, twice the force is produced for the larger RVE as expected. For HBC, the smaller RVE produces a slightly stiffer response than the larger RVE. Furthermore, it is noted that the same force response is produced by the larger RVE for both $\mathrm{PBC}$ and $\mathrm{HBC}$, indicating that the force has converged.

For the equivalent material formulation adopted for the homogenized core the mechanical response of the
Fig. 9 In-plane shear stress is illustrated for an example where a comparison between periodic and homogeneous boundary conditions is made under in-plane shear loading
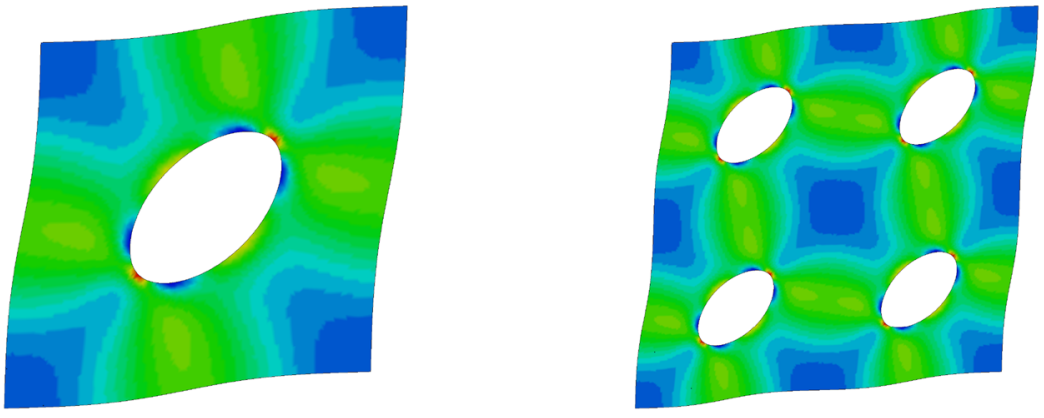

(a) One unit cell and periodic boundary conditions. Force $=207.2 \mathrm{kN}$.

(b) Four unit cells and periodic boundary conditions. Force $=414.4 \mathrm{kN}$.
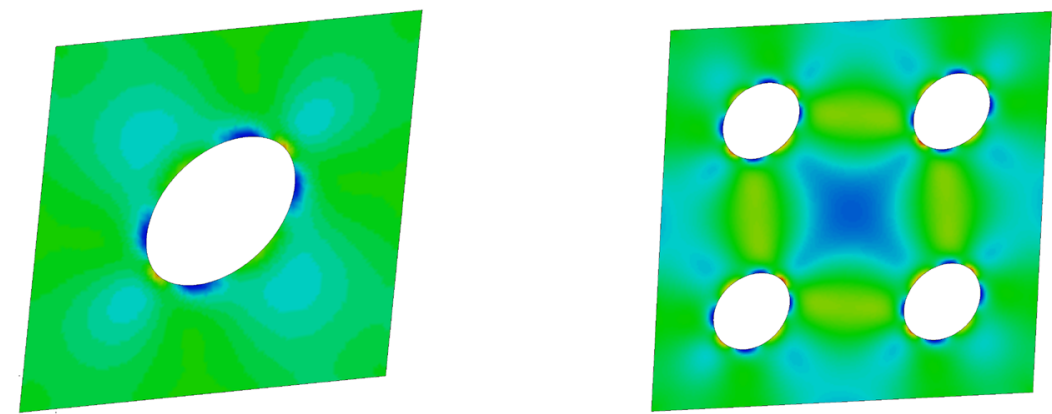

(c) One unit cell and homogeneous boundary conditions. Force $=233.4 \mathrm{kN}$. (d) Four unit cells and homogeneous boundary conditions. Force $=441.2 \mathrm{kN}$. 
Fig. 10 In-plane shear stress is illustrated for the Type A RVE where a comparison between periodic and homogeneous boundary conditions is made under in-plane shear loading

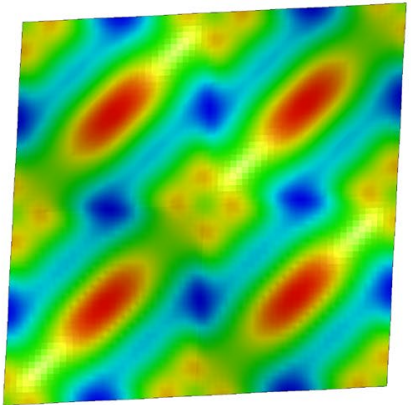

(a) One unit cell and periodic boundary conditions. Force $=38.2 \mathrm{kN}$.

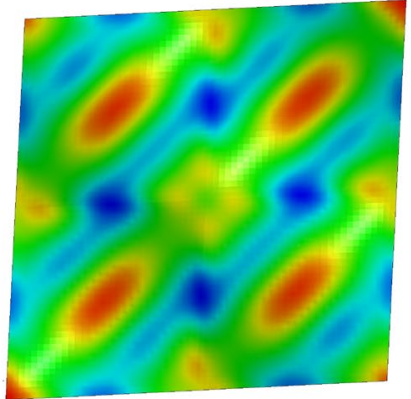

(c) One unit cell and homogeneous boundary conditions. Force $=38.3 \mathrm{kN}$.

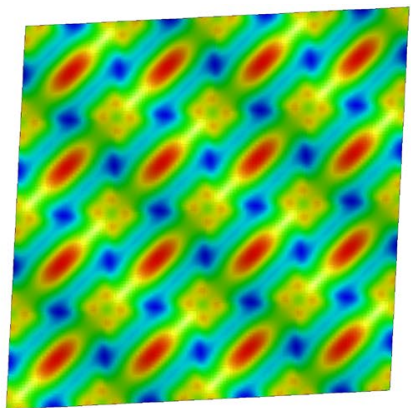

(b) Four unit cells and periodic boundary conditions. Force $=76.4 \mathrm{kN}$

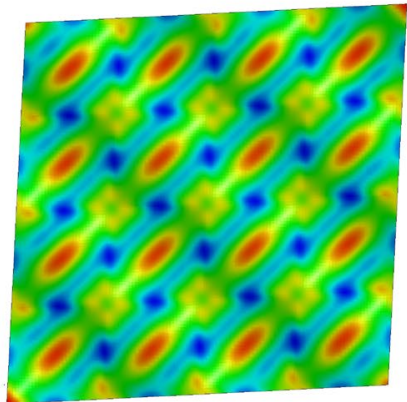

(d) Four unit cells and homogeneous boundary conditions. Force $=76.4 \mathrm{kN}$. cores is determined by characterizing the ABD-matrix of an RVE for each core. A mesh convergence study is conducted for each component of the ABD-matrix to ensure mesh independent results. Data for several levels of mesh refinement is presented in Table 1 for each component of the ABD-matrix. The in-plane behavior of the two cores only differs by a few percent and can be considered quite equivalent. Difference in bending is more prominent but since this behavior is dominated by the face plates the observed difference can be ignored.

In Fig. 11a the obtained results from the experimental three-point bending are presented for three specimens with the Type A core named Panel 01, Panel 02 and Panel 03 . A variation in the response is observed. A challenge when welding the face plates to the core is the small welding area for the Type A core. Thus, core geometry deviations or non plane face plates can result in welds that do not join the core and face plates. This is a possible cause for the observed differences in the force-displacement response along with other geometrical variations derived from manufacturing. This motivates the introduction of the Type B core with flattened peaks allowing for a larger welding area. However, the affect of the increased area on adhesion is not studied in the present work just how this change in geometry affects mechanical properties.
Table 1 Characterized elastic components of the ABD-matrix for the Type A and B RVEs. Three levels of mesh refinement are presented for each constant to illustrate convergence for each component of the ABD-matrix. $A_{i j}$ is given in $\mathrm{MN} / \mathrm{m}$ whereas $D_{i j}$ is given in $\mathrm{Nm}$

Average edge length of shell element $(\mathrm{mm})$

\begin{tabular}{llll}
\hline 0.5 & 0.25 & 0.125 & 0.0625
\end{tabular}

\begin{tabular}{lrrrr}
\hline Type $A$ & & & & \\
$A_{11}=A_{22}$ & 47.1 & 46.9 & 46.8 & 46.8 \\
$A_{12}$ & -13.8 & -13.9 & -13.9 & -13.9 \\
$A_{66}$ & 31.2 & 31.2 & 31.2 & \\
$D_{11}=D_{22}$ & 3.19 & 3.14 & 3.13 & 3.13 \\
$D_{12}$ & -0.45 & -0.38 & -0.38 & -0.38 \\
$D_{66}$ & & 3.82 & 3.80 & 3.80 \\
Type $B$ & & & & \\
$A_{11}=A_{22}$ & 37.1 & 36.5 & 36.4 & 36.4 \\
$A_{12}$ & -10.8 & -11.1 & -11.1 & -11.1 \\
$A_{66}$ & 30.0 & 30.0 & 30.0 & \\
$D_{11}=D_{22}$ & 4.3 & 4.2 & 4.1 & 4.1 \\
$D_{12}$ & -0.64 & -0.41 & -0.35 & -0.35 \\
$D_{66}$ & & 5.11 & 5.06 & 5.05 \\
\hline
\end{tabular}


Fig. 11 Results from the experiments and simulations

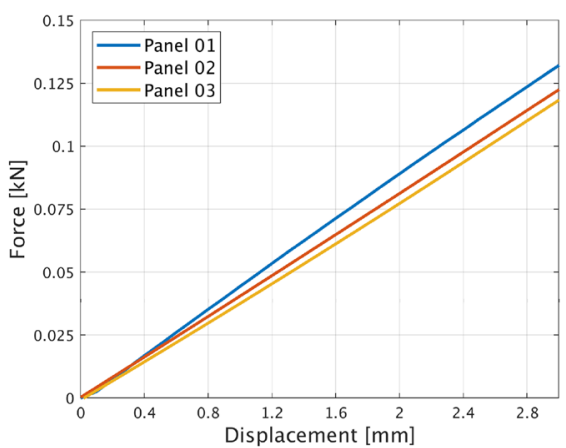

(a) Experimental results for the manufactured Type A sandwiches.

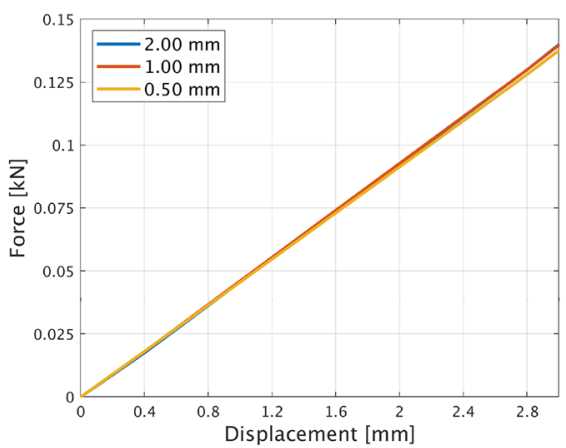

(c) Detailed model of Type B for three different mesh sizes.

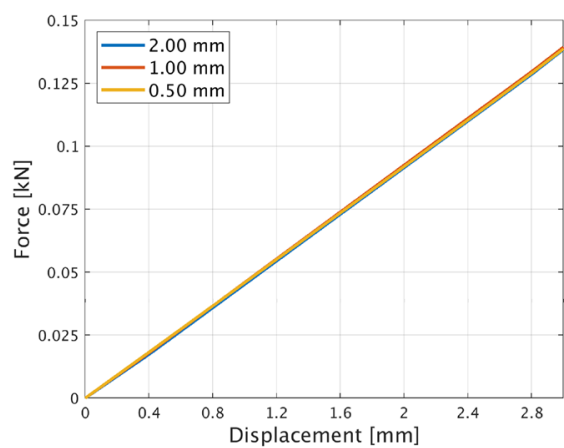

(b) Detailed model of Type A for three different mesh sizes.

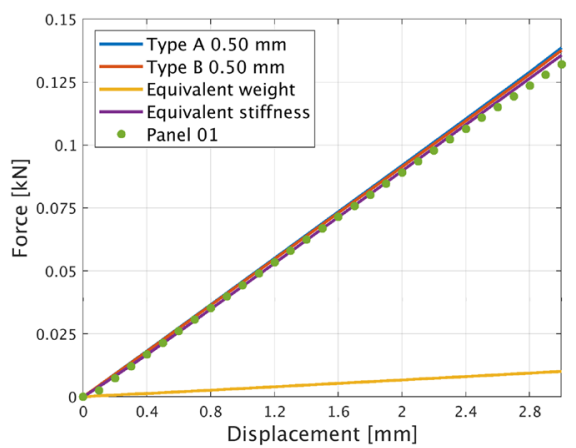

(d) The numerical models with mesh size 0.5 $\mathrm{mm}^{2}$ is compared against the manufactured specimen Panel 01 and a solid panel of equivalent weight to the sandwich.
Numerical models of the three-point bending are created and to verify mesh independent results three mesh sizes of 2, 1 and $0.5 \mathrm{~mm}$ are compared for the Type $A$ and $B$ sandwiches. The results are presented in Fig. $11 \mathrm{~b}, \mathrm{c}$ where it is clear that mesh independent results are obtained for the current application. Much finer meshes are required for the convergence when characterizing the RVEs as compared to the three-point bending, indicating that the mechanical properties of the core is subordinate the response of the face plates during three-point bending as expected. This also indicates that finer meshes of the core might be necessary if other load cases are studied where out-of-the-plane bending is less prominent. Panel 01 produced the stiffest response from the manufactured specimens and is chosen when compared with the force-displacement response of the detailed Type $A$ and $B$ finite element models. This is presented in Fig. 11d. The experimental and simulated results agree well, and the change of core geometry from Type A to B does not have a significant impact on the force-displacement response.

In the figure, a comparison is also made with panels of equivalent weight and stiffness to the sandwich in order to illustrate the superior specific bending stiffness
$(\mathrm{N} /(\mathrm{m} \mathrm{kg}))$ and weight saving potential of the sandwich. The sandwich weighs $42 \%$ of a solid panel of equivalent bending stiffness.

Finally, the homogenized models of the Type A and Type B sandwich are presented in Fig. 12 and compared with their corresponding detailed models. The obtained constants for the ABD-matrices for the Type A and Type $B$ RVEs are presented in Table 1. The response for the detailed and homogenized models agree well, with the homogenized model showing a slightly stiffer response. This is not surprising since the core is slightly compressed during three-point bending reducing height and thereby stiffness. By utilizing the homogenized models the numbers of elements were reduced from 11,536 to 992 if the coarsest mesh $(2 \mathrm{~mm})$ of the detailed core is used and compared to an equivalent panel with the same mesh size. The difference in computational time is 566 compared to $87 \mathrm{~s}$. The great reduction in computational time is of importance if such panels are to be used in the industry. Consideration is only taken to elastic stiffness for small deformations. Plasticity and geometrical non-linearities are not considered for the current application. 
Fig. 12 A comparison is made between the detailed models and the homogenized models

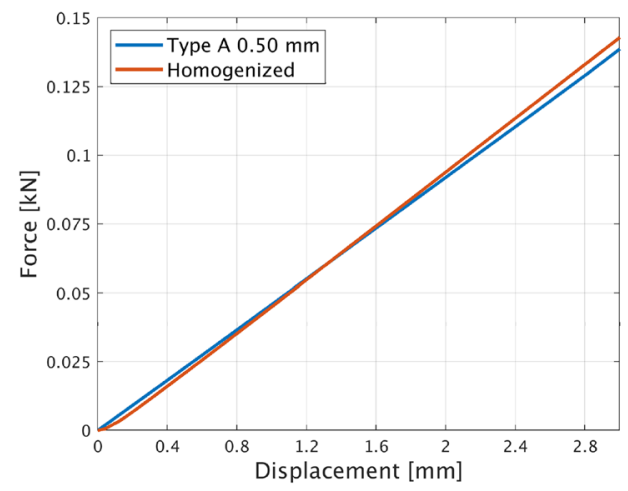

(a) Type A.

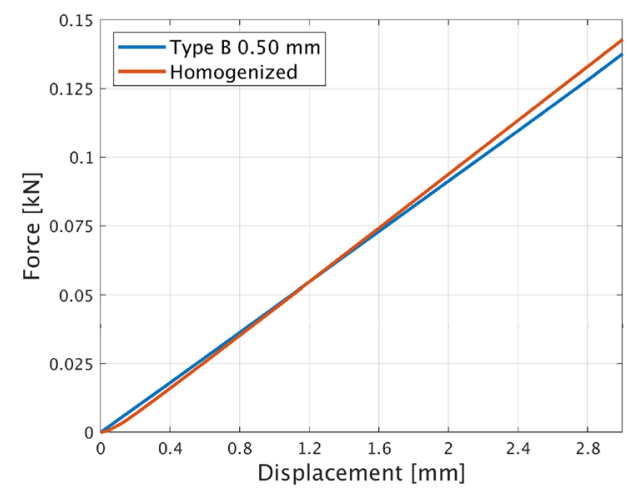

(b) Type B.

\section{Discussion and conclusions}

There is a need for light and strong materials. By utilizing UHSS it has been possible to improve the strength to weight ratio in many applications. For further improvement, sandwich panels based on UHSS may be developed and used in component design. In this work, two types of UHSS sandwich panels are presented: Type A and Type B. A pilot-scale mill is used to show that Type A can be manufactured in a continuous manner. The success with manufacturing the core in the pilot-scale mill indicates that large-scale production is plausible, which would be beneficial with regard to production costs. The manufactured panels are tested in three-point bending and the results are shown in Fig. 11a where a spread in the response is observed due to inconsistencies in the manufacturing process, such as the exact placement of the welds. Numerical models are created in order to recreate the force-response of the manufactured specimens. Good agreement is found with the manufactured panel exhibiting the stiffest response. This is not surprising since imperfections are not included in the numerical models thus generally creating a stiffer response than real panels. From the comparison between the two types of cores it is concluded that the change made in the geometry by flattening the peaks of the core does not have a significant impact on flexural stiffness. Thus, it is possible to increase the welding area for better bonding while maintaining geometrical stiffness.

The corrugated core is characterized by subjecting an RVE to several load cases. Studying an RVE instead of larger structures is motivated since it reduces computational time. An early definition was provided by Hill [53], stating that a representative volume should structurally be entirely typical of the material at large. Thus, motivating the choice of the unit cell as the RVE throughout the present study. Furthermore, the RVE should be of sufficient size so that stress and the displacement vectors on the boundary of the RVE will fluctuate about a mean value with a wavelength small compared to the RVE size, as described by Suquet [47]. Furthermore, statistical homogeneity is necessary (Ostoja-Starzewski [54]), so that measurements made on the RVE are representative for the macro scale of the material. It is clear from the stress fields in Figs. 9 and 10, as well as from the force response, that the RVE size is not sufficient for HBC and that the influence of the boundary conditions is large. However, for the Type A RVE with one unit cell, this influence is not as tangible since the force response is approximately the same for both $\mathrm{HBC}$ and $\mathrm{PBC}$. The reason for the difference in response for $\mathrm{HBC}$ is the lack of maintained periodicity. This occurs when the boundary edges are forced to remain plane after deformation. However, if an isotropic, homogeneous RVE is considered, periodicity would be achieved by HBC but for an orthotropic RVE, such boundary conditions over (or under) predict stiffness, Suquet [47], Xia et al. [48], Omairey et al. [49]. This is especially clear from the forces obtained in Fig. 9. Thus, in general if a periodic media is studied where the unit cell is chosen as the RVE, $\mathrm{HBCs}$ are not applicable, as shown by the simple example of Fig. 9. For HBC a convergence study must be performed with respect to the number of unit cells required for the parameters of interest to converge. The convergence study is done to ensure that the chosen volume element is in fact an RVE of the material at the macro scale, which is computationally costly and time consuming and partly avoided if periodic boundary conditions are adopted.

Periodic boundary conditions allow the RVE to move more freely so that plane boundaries do not necessarily remain plane after deformation. Once the PBC has been implemented into the finite element model a check can me made that the boundary conditions are in fact periodic. This is done by creating a model with twice the amount of unit cells in each direction and applying the same boundary conditions. The same stress field should be obtained with one unit cell as with any amount of unit cells. This is the strength of the PBC, that the response of an infinite model with unit cells is obtained when analyzing just one unit cell. 
An illustrative example, showing the difference in response when comparing homogeneous and periodic boundary conditions by utilizing the quadratic RVE is presented in Fig. 9. Thus, if homogeneous boundary conditions are used a convergence check must be made with regard to RVE size as to not over/under predict stiffness. As is seen in this work, for the periodic structure of the Type A core only small differences were observed when comparing PBCs and HBCs indicating that either type of boundary conditions can be adopted. However, this does not hold for the general case where PBCs should be used to ensure periodicity.

In conclusion, this work contributes by presenting a novel concept of lightweight UHSS sandwiches with high specific stiffness. It is shown that the UHSS sandwich panels can be manufactured in a continuous manner, making it reasonable to think that production of larger panels should be possible. An important conclusion from this work is that UHSS sandwich panels show promising lightweight properties and can be an important solution for light and strong components.

The main conclusion of the present work is that the equivalent material formulation accurately predicts structural stiffness of the sandwich panels while drastically reducing computational time. The reduction of computational time is essential for sandwich materials to be of interest for industrial use. Periodic boundary conditions are adopted to not over/under predict stiffness of the in-plane mechanical properties and to maintain periodicity. It is further concluded that by applying periodic boundary conditions to the unit cell of the core, an equivalent material formulation provides a tool for modeling such panels in an efficient manner with respect to computational time and with maintained accuracy. This makes it possible to incorporate such equivalent panels into larger finite element models as a computationally efficient alternative to detailed finite element models.

Acknowledgements Open access funding provided by Lulea University of Technology. The authors want to thank Mr. Jan Granström for assistance and expertise during the experimental work. Furthermore, the authors acknowledge Swerim for the development of the patterned rolls for core manufacturing. Economic support is supplied through the Swedish lightweight innovation programme-LIGHTer, which is gratefully acknowledged.

\section{Compliance with ethical standards}

Conflict of interest On behalf of all authors, the corresponding author states that there is no conflict of interest.

Open Access This article is licensed under a Creative Commons Attribution 4.0 International License, which permits use, sharing, adaptation, distribution and reproduction in any medium or format, as long as you give appropriate credit to the original author(s) and the source, provide a link to the Creative Commons licence, and indicate if changes were made. The images or other third party material in this article are included in the article's Creative Commons licence, unless indicated otherwise in a credit line to the material. If material is not included in the article's Creative Commons licence and your intended use is not permitted by statutory regulation or exceeds the permitted use, you will need to obtain permission directly from the copyright holder. To view a copy of this licence, visit http://creativecommons .org/licenses/by/4.0/.

\section{References}

1. Garrison WM (1990) Ultrahigh-strength steels for aerospace applications. JOM 42(5):20-24. https://doi.org/10.1007/BF032 20942 (ISSN 10474838)

2. Tomita Y (1991) Development of fracture toughness of ultrahigh strength low alloy steels for aircraft and aerospace applications. Mater Sci Technol (UK) 7(6):481-489. https:// doi.org/10.1179/mst.1991.7.6.481 (ISSN 17432847)

3. Tomita $Y(2000)$ Development of fracture toughness of ultrahigh strength, medium carbon, low alloy steels for aerospace applications. Int Mater Rev 45(1):27-37. https://doi. org/10.1179/095066000771048791 (ISSN 09506608)

4. Paules JR, Dilmore MF, Handerhan KJ (2005) Development of Eglin steel-a new, ultrahigh-strength steel for armament and aerospace applications. Mater Sci Technol 2:13-23 (ISBN 0873396456)

5. Fan HM, Zeng YP, Wang XS, Cui ZQ, Xie XS (2007) Study on inclusion induced fatigue crack initiation and propagation in ultra-high strength steel for aerospace application. Kang T'ieh/Iron and Steel (Peking) 42(7), July. ISSN 0449749X

6. Wang C, Zeng YP, Xie XS (2009) Influence of characteristic inclusion parameters on crack initiation and propagation in ultra-high strength steels for aerospace application under tensile and low cyclic fatigue loading. Beijing Keji Daxue Xuebao/J Univ Sci Technol Beijing 31(5):557-562 (ISSN 1001053X)

7. Raiyan S, David S, Bing Z, Austin W, Sean G, Philip F, Alaa E, Raymundo A, Ibrahim K (2020) An ultra-high strength martensitic steel fabricated using selective laser melting additive manufacturing: densification, microstructure, and mechanical properties. Acta Mater. https://doi.org/10.1016/j.actamat.2019.12.037 (ISSN 13596454)

8. Anon (1994) Ultra-high-strength steel for ship's propellers. Diesel Gas Turbine Worldw 26(9):33 ISSN 02785994

9. Zhou H, Jiang ZY, Liu JF, Zheng X, Hu XC, Zhu YL (2017) Research on ultra large container ship ultra-high-strength steel EH47 welding residual stress simulation and experiment. Chuan Bo Li Xue/J Ship Mech 21(8):993-1000. https://doi.org/10.3969/j. issn.1007-7294.2017.08.008 (ISSN 10077294)

10. Karbasian H, Tekkaya AE (2010) A review on hot stamping. J Mater Process Technol 210(15):2103-2118. https://doi. org/10.1016/j.jmatprotec.2010.07.019 (ISSN 09240136)

11. Oldenburg $M$, Lindkvist $G$ (2011) Tool thermal conditions for tailored material properties. HTM J Heat Treat Mater 66(6):329-334. https://doi.org/10.3139/105.110121 (ISSN 1867-2493)

12. Oldenburg M (2014) Warm forming of steels for tailored microstructure. https://doi.org/10.1007/978-94-007-2739-7

13. Merklein M, Wieland M, Lechner M, Bruschi S, Ghiotti A (2016) Hot stamping of boron steel sheets with tailored properties: a review. J Mater Process Technol 228:11-24. https://doi. org/10.1016/j.jmatprotec.2015.09.023 (ISSN 09240136)

14. Bergman $G$ (1999) Modelling and simulation of simultaneous forming and quenching. PhD thesis. Luleå University of Technology, Luleå

15. Eriksson $M$, Oldenburg $M$, Somani MC, Karjalainen LP (2002) Testing and evaluation of material data for analysis of forming and hardening of boron steel components. 
Modell Simul Mater Sci Eng 10(3):277-294. https://doi. org/10.1088/0965-0393/10/3/303

16. Bergman G, Oldenburg M (2004) A finite element model for thermomechanical analysis of sheet metal forming. Int J Numer Methods Eng 59(9):1167-1186. https://doi.org/10.1002/ nme.911 (ISSN 00295981)

17. Åkerström $P$, Wikman $B$, Oldenburg $M(2005)$ Material parameter estimation for boron steel from simultaneous cooling and compression experiments. Modell Simul Mater Sci Eng 13(8):1291-1308. https://doi.org/10.1088/0965-0393/13/8/007 (ISSN 09650393)

18. Åkerström $\mathrm{P}$, Oldenburg M (2006) Austenite decomposition during press hardening of a boron steel-computer simulation and test. J Mater Process Technol 174(1-3):399-406. https://doi. org/10.1016/j.jmatprotec.2006.02.013 (ISSN 09240136)

19. Paul $\AA$, Greger B, Mats $O$ (2007) Numerical implementation of a constitutive model for simulation of hot stamping. Modell Simul Mater Sci Eng. https://doi.org/10.1088/0965-0393/15/2/007

20. Östlund R, Oldenburg M, Häggblad HÅ, Berglund D (2014) Evaluation of localization and failure of boron alloyed steels with different microstructure compositions. J Mater Process Technol. https ://doi.org/10.1016/j.jmatprotec.2013.09.022 (ISSN 09240136)

21. Rickard Ö, Mats O, Hans AH, Daniel B (2015) Numerical failure analysis of steel sheets using a localization enhanced element and a stress based fracture criterion. Int J Solids Struct. https:// doi.org/10.1016/j.ijsolstr.2014.12.010 (ISSN 00207683)

22. Golling S, Östlund R, Oldenburg M (2016) Characterization of ductile fracture properties of quench-hardenable boron steel: influence of microstructure and processing conditions. Mater Sci Eng, A 658:472-483. https://doi.org/10.1016/j.msea.2016.01.091 (ISSN 09215093)

23. Parareda S, Casellas D, Frómeta D, Martínez M, Lara A, Barrero A, Pujante J (2020) Fatigue resistance of press hardened 22MnB5 steels. Int J Fatigue. https://doi.org/10.1016/j.jjfatigue.2019.105262

24. Johnson AF, Sims GD (1986) Mechanical properties and design of sandwich materials. Composites 17(4):321-328. https://doi. org/10.1016/0010-4361(86)90749-4 (ISSN 00104361)

25. Reyes A, Hopperstad OS, Berstad T, Hanssen AG, Langseth M (2003) Constitutive modeling of aluminum foam including fracture and statistical variation of density. Eur J Mech A/Solids 22(6):815835. https://doi.org/10.1016/j.euromechsol.2003.08.001 (ISSN 09977538)

26. Deshpande VS, Fleck NA (2000) Isotropic constitutive models for metallic foams. J Mech Phys Solids 48(6):1253-1283. https://doi. org/10.1016/S0022-5096(99)00082-4 (ISSN 00225096)

27. Zhang Y, Sun G, Xipeng X, Li G, Huang X, Shen J, Li Q (2013) Identification of material parameters for aluminum foam at high strain rate. Comput Mater Sci 74:65-74. https://doi.org/10.1016/j.comma tsci.2013.02.024 (ISSN 09270256)

28. Rostamiyan Y, Norouzi H (2016) Flatwise compression strength and energy absorption of polyurethane foam-filled lattice core sandwich panels. Strength Mater. https://doi.org/10.1007/s1122 3-017-9827-y

29. Guo K, Zhu L, Li Y, Yu TX (2019) Numerical study on mechanical behavior of foam core sandwich plates under repeated impact loadings. Compos Struct. https://doi.org/10.1016/j.compstruct .2019.111030 (ISSN 02638223)

30. Aktay L, Johnson AF, Kröplin BH (2008) Numerical modelling of honeycomb core crush behaviour. Eng Fract Mech 75(9):26162630. https://doi.org/10.1016/j.engfracmech.2007.03.008 (ISSN 00137944)

31. Nayak SK, Singh AK, Belegundu AD, Yen CF (2013) Process for design optimization of honeycomb core sandwich panels for blast load mitigation. Struct Multidiscip Optim 47(5):749-763. https:// doi.org/10.1007/s00158-012-0845-x (ISSN 1615147X)
32. Liu PF, Li XK, Li ZB (2017) Finite element analysis of dynamic mechanical responses of aluminum honeycomb sandwich structures under low-velocity impact. J Failure Anal Prev. https://doi. org/10.1007/s11668-017-0358-4

33. Wang J, Bihamta R, Morris TP, Pan YC (2019) Numerical and experimental investigation of a laminated aluminum composite structure. Appl Compos Mater 26(4):1177-1188. https://doi. org/10.1007/s10443-019-09773-7 (ISSN 15734897)

34. Jones RM (1999) Mechanics of composite materials, 2nd edn. TayIor \& Francis Group, Berlin (ISBN 9781560327127$)$

35. Biancolini ME (2005) Evaluation of equivalent stiffness properties of corrugated board. Compos Struct 69(3):322-328. https://doi. org/10.1016/j.compstruct.2004.07.014 (ISSN 02638223)

36. Kress G, Winkler M (2010) Corrugated laminate homogenization model. Compos Struct 92(3):795-810. https://doi.org/10.1016/j. compstruct.2009.08.027 (ISSN 02638223)

37. Li S (2008) Boundary conditions for unit cells from periodic microstructures and their implications. Compos Sci Technol 68(9):19621974. https://doi.org/10.1016/j.compscitech.2007.03.035 (ISSN 02663538)

38. Iman D, Saeed Z-R, Hamid S (2012) Numerical and experimental investigations on mechanical behavior of composite corrugated core. Appl Compos Mater. https://doi.org/10.1007/s1044 3-011-9238-3

39. Xia Y, Friswell MI, Flores EIS (2012) Equivalent models of corrugated panels. Int J Solids Struct 49(13):1453-1462. https://doi. org/10.1016/j.ijsolstr.2012.02.023 (ISSN 00207683)

40. Ye Z, Berdichevsky VL, Yu W (2014) An equivalent classical plate model of corrugated structures. Int J Solids Struct 51:2073-2083. https://doi.org/10.1016/j.ijsolstr.2014.02.025

41. Marek A, GarbowskiT (2015) Homogenization of sandwich panels. Comput Assisted Methods Eng Sci 22:39-50 (ISSN 16310721)

42. Jo PK, Kang J, Wann KY (2016) Evaluation of homogenized effective properties for corrugated composite panels. Compos Struct. https://doi.org/10.1016/j.compstruct.2016.01.002 (ISSN 02638223)

43. Suphattharachai $C$, Manit $L$ (2011) Finite element study of the stress response of bi-directional corrugated-strip core sandwich beam. J Comput Sci. https://doi.org/10.3844/ajassp.2010.840.845 (ISSN 1546-9239)

44. Besse Camille C, Dirk M (2012) Optimization of the effective shear properties of a bidirectionally corrugated sandwich core structure. J Appl Mech 80(1):011012. https://doi.org/10.1115/1.40069 41 (ISSN 0021-8936)

45. Daliri V, Zeinedini A (2019) Flexural behavoiur of the composite sandwich panels with novel and regular corrugated cores. Appl Compos Mater. https://doi.org/10.1007/s10443-019-09761-x

46. Bartolozzi G, Pierini M, Orrenius U, Baldanzini N (2013) An equivalent material formulation for sinusoidal corrugated cores of structural sandwich panels. Compos Struct 100:173-185. https://doi. org/10.1016/j.compstruct.2012.12.042 (ISSN 02638223)

47. Pierre $S$ (1987) Elements of homogenization theory for inelastic solid mechanics. In: Sanchez-Palencia E, Zaoui A (eds) Homogenization techniques for composite media. Springer, Berlin, pp 194-275

48. Zihui X, Yunfa Z, Fernand E (2003) A unified periodical boundary conditions for representative volume elements of composites and applications. Int J Solids Struct 40(8):1907-1921. https://doi. org/10.1016/S0020-7683(03)00024-6 (ISSN 00207683)

49. Omairey SL, Dunning PD, Sriramula S (2019) Development of an ABAQUS plugin tool for periodic RVE homogenisation. Eng Comput 35(2):567-577. https://doi.org/10.1007/s00366-018-0616-4 (ISSN 14355663)

50. LSTC (2017) LS-DYNA keyword user's manual-vol. 2-v971 build R9.1.0. Technical report. www.Istc.com 
51. Wu CT, Hu W (2017) Representative volume element (RVE). FEA Inf Eng J 6(Q2):17-20

52. Liu Z, Wu CT, Ren B, Liu WK, Grimes Roger 5th international LSDYNA users conference multiscale simulations of material with heterogeneous structures based on representative volume element techniques. Technical report

53. Hill R (1963) Elastic properties of reinforced solids: some theoretical principles. J Mech Phys Solids. https://doi.org/10.1016/00225096(63)90036-X (ISSN 00225096)
54. Ostoja-Starzewski M (2002) Microstructural randomness versus representative volume element in thermomechanics. J Appl Mech. https://doi.org/10.1115/1.1410366

Publisher's Note Springer Nature remains neutral with regard to jurisdictional claims in published maps and institutional affiliations. 